Research Article

\title{
A comparative study of adverse reactions of taxol and non taxol based chemotherapy regimens in breast cancer
}

\author{
Geetha Rani*, Dulcie Celia, Ezhil Ramya, Meenakshi Balasubramanium
}

Department of Pharmacology, Tirunelveli medical college, Tirunelveli, Tamilnadu, India

Received: 16 June 2016

Accepted: 08 July 2016

\section{*Correspondence to:}

Dr. Geetha Rani,

Email: drgeetha81@gmail.com

Copyright: (C) the author(s), publisher and licensee Medip Academy. This is an openaccess article distributed under the terms of the Creative Commons Attribution NonCommercial License, which permits unrestricted noncommercial use, distribution, and reproduction in any medium, provided the original work is properly cited.

\begin{abstract}
Background: The incidence of breast cancer is increasing in India. A combination of medicines is typically used to treat breast cancer. All the medications used in treatment are associated with various side effects. So this study is done to estimate and compare the adverse reactions of taxol and nontaxol based chemotherapy regimens in breast cancer patients attending Tirunelveli Medical College Hospital.

Methods: The study was conducted in the oncology ward at TVMCH for a period of 60 days from August $2^{\text {nd }}$ October $2^{\text {nd }} 2014$. Patients with unilateral or bilateral carcinoma breast with or without metastasis, receiving chemotherapy were included. Medication details such as the type of regimen, dose, and duration of regimen and relevant data of lab investigations were collected. 30 patients who fulfilled study criteria were included, out of which 16 were assigned FAC (5flurouracil, adriamycin, cyclophosphamide) regimen and 14 were assigned PAC (paclitaxel, adriamycin, cyclophosphamide) regimen.

Results: The incidence of adverse reactions like myelodepression resulting in Neutropenia (64.28\%), Anaemia (57\%) and Thrombocytopaenia (21\%) was comparatively higher with PAC regimens than FAC regimen. Nausea $(75 \%)$ and vomiting (43\%) was found to be higher with FAC regimen despite antiemetic use. No serious adverse reactions occurred in either regimens.

Conclusions: The adverse reaction profile of FAC regimen was found to be favourable than PAC therapy though not statistically significant, with no references to efficacy and potency of these regimens in the treatment of breast cancer patients with or without metastasis.
\end{abstract}

Keywords: Breast cancer, Paclitaxel, 5-Flurouracil, Adverse reactions

\section{INTRODUCTION}

Breast cancer is the most common cancer in women worldwide, with nearly 1.7 million new cases diagnosed (second most common cancer overall). ${ }^{1}$ With rising incidence and awareness, breast cancer is the commonest cancer in urban Indian females, and the second commonest in the rural Indian women. ${ }^{2}$ Both the morbidity and mortality are high in India with an estimated 70, 218 deaths. ${ }^{1}$ Such high mortality rate can be attributed to the lack of adequate knowledge about breast cancer at the root level leading to delay in approaching the medical services and lack of sufficient medical facilities at all levels.
This study was concerned about the adverse reactions associated with neo-adjuvant and adjuvant chemotherapy given to breast cancer patients. The various drugs available include paclitaxel, docetaxel, adriamycin, cyclophosphamide, 5-flurouracil, each having its own profile of adverse reactions. The use of combination chemotherapy has been associated with increased response rates as compared with a single agent. ${ }^{3}$ The common drug combinations adopted in our government setup was paclitaxel, adriamycin, cyclophosphamide (PAC) and 5-flurouracil, adriamycin, cyclophosphamide (FAC). Paucity of data exists regarding the adverse reactions of these drug regimens adopted in TVMCH. This study was therefore undertaken to compare and 
analyse the adverse reactions of taxol and non-taxol based chemotherapy regimens that were commonly employed in the treatment of breast cancer patients attending TVMCH.

\section{METHODS}

The centre of this study was oncology Department, Tirunelveli medical college hospital. The design of this study was prospective observational study. The period of this study was from August 2014 to October 2014.

\section{Inclusion criteria}

- Female subjects aged above 18 years

- Histologically and cytologically confirmed invasive mammary carcinoma

- Patients with or without metastasis.

\section{Exclusion criteria}

- Male patients

- Patients not willing to sign informed consent

- Concurrent radiotherapy or chemotherapy for any other tumour

- Any active infections, HIV, hepatitis B, C

- Pregnant and lactating women.

All patients diagnosed with carcinoma breast during the study period of 60 days (August $2^{\text {nd }}-0$ ctober $2^{\text {nd }} 2014$ ), satisfying the selection criteria, scheduled for or receiving either PAC or FAC regimens were enrolled for this study.

\section{The choice of the regimen for a patient is determined by}

- Total blood count of the patient at the time of chemotherapy

- Hemoglobin level of the patient

- Age of the patient

- Nature and progression of the disease.

A complete physical examination, clinical assessment, and all baseline investigations were done before commencing of the study, between 2 cycles of chemotherapy and at study termination. The samples were sent to central diagnostic laboratory, TVMCH.

Mitigation of avoidable adverse reactions of these regimens were done using premedicative drugs like dexamethasone, ondensteron, ranitidine and antihistamine in varying doses for each patient depending upon the regimen adopted.

Paclitaxel was given at a dose of $175-325 \mathrm{mg} / \mathrm{m}^{2}$ depending upon the patient as an iv infusion along with normal saline at a rate of 15 drops per minute lasting for about 3 hours. ${ }^{4}$ The premedications given were dexamethasone, ondensteron and ranitidine.
5-Flurouracil was given at a dose of $500 \mathrm{mg} / \mathrm{m} 2$ as direct IV over a period of 10 minutes, the dose slightly varies with the patient. ${ }^{4}$ The premedications given were dexamethasone, ondensteron and ranitidine.

Cyclophosphamide was given at a dose of 400-800 mg direct IV over 10 minutes. Adriamycin, 50-80 mg dosage as slow IV with simultaneous normal saline drip. ${ }^{4}$

Adverse reactions were noted throughout the study and classified as mild, moderate and severe according to the WHO scale of adverse reactions. The adverse reactions were summarized using descriptive statistics.

\section{RESULTS}

Among 200 female patients admitted in the oncology ward during the study period of 60 days (August $2^{\text {nd }}$ October $\left.2^{\text {nd }} 2014\right)$, 30 were diagnosed to have breast cancer of which $16(53 \%)$ were on FAC regimen and 14 (47\%) on PAC regimen. Adverse reactions were reported in all patients. These were analysed using chi-square test and the $\mathrm{p}$ value was calculated (Table 1).

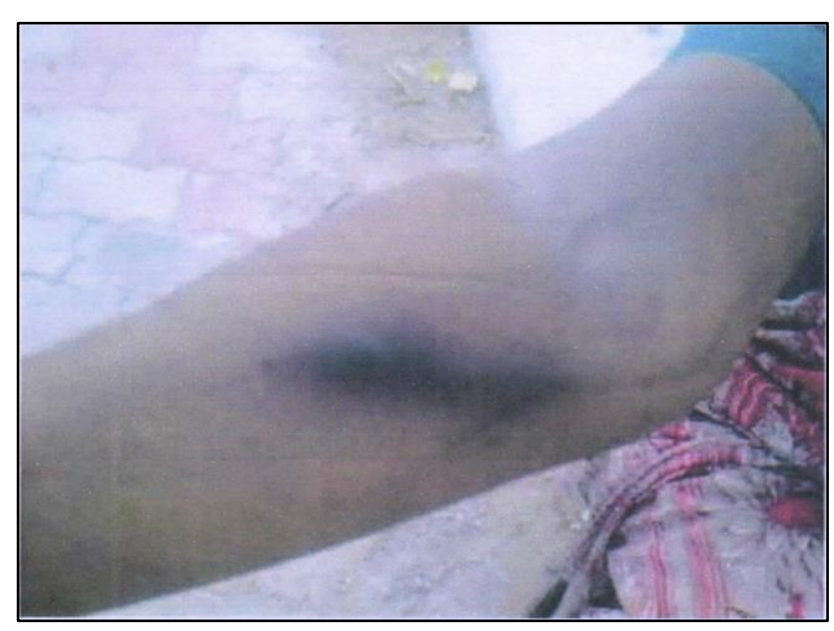

Figure 1: Thrombophlebitis in PAC regimen.

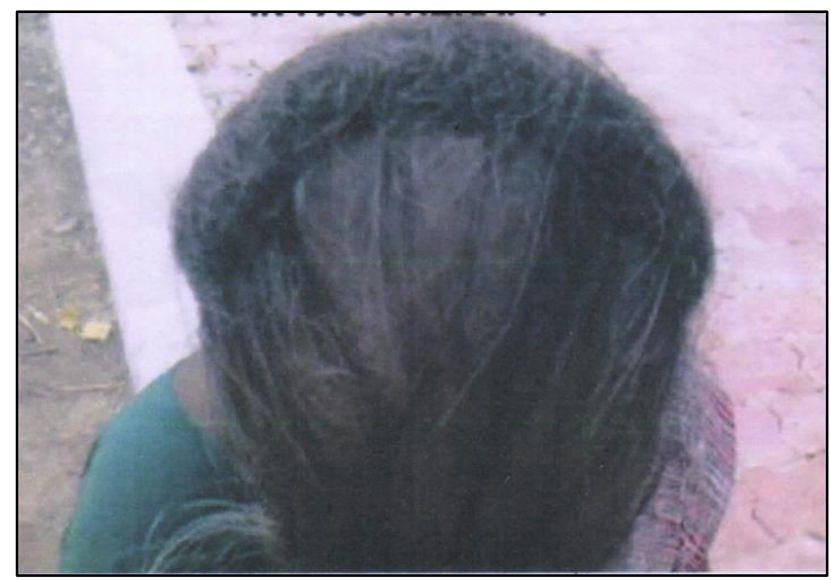

Figure 2: Alopecla in PAC therapy. 
Most common adverse reactions reported with PAC regimen include alopecia followed by neutropenia and for FAC regimen were alopecia followed by nausea and vomiting.

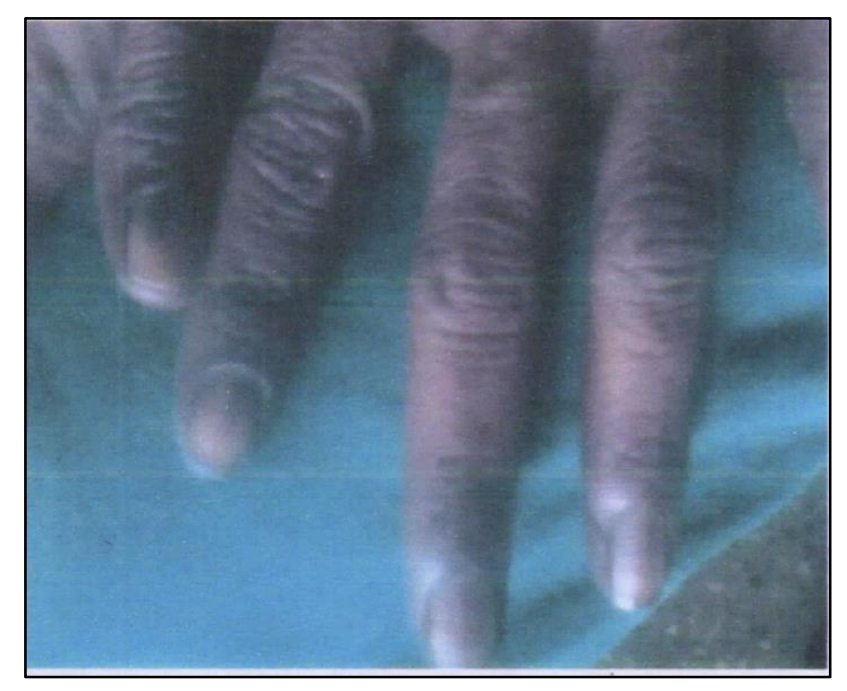

Figure 3: Melanonychla of hands in PAC therapy.

Table 1: Adverse effect profile of both PAC and FAC regimens.

\begin{tabular}{|c|c|c|c|}
\hline $\begin{array}{l}\text { Adverse } \\
\text { reactions }\end{array}$ & $\begin{array}{l}\text { PAC } \\
\text { regimen } \\
(n=14)\end{array}$ & $\begin{array}{l}\text { FAC } \\
\text { regimen } \\
(n=16)\end{array}$ & $P$ value \\
\hline $\begin{array}{l}\text { Nausea and } \\
\text { vomiting }\end{array}$ & $5(35.71 \%)$ & $12(75 \%)$ & 0.030287 \\
\hline Alopecia & $13(92.85 \%)$ & $13(81.25 \%)$ & 0.601533 \\
\hline Fatigue & $8(57.14 \%)$ & $7(43.75 \%)$ & 0.464215 \\
\hline Giddiness & $4(28.57 \%)$ & $4(25 \%)$ & 0.690821 \\
\hline Leg cramps & $2(14.28 \%)$ & $2(12.5 \%)$ & 1 \\
\hline Melononychia & $8(57.14 \%)$ & $9(56.25 \%)$ & 0.57649 \\
\hline Groin pain & $1(7.14 \%)$ & & 0.428571 \\
\hline $\begin{array}{l}\text { Abdominal } \\
\text { pain }\end{array}$ & $2(14.28 \%)$ & $2(12.5 \%)$ & 1 \\
\hline $\begin{array}{l}\text { Loss of } \\
\text { appetite }\end{array}$ & & $3(18.75 \%)$ & 0.238095 \\
\hline Pruritus & $4(28.57 \%)$ & $4(25 \%)$ & 0.690821 \\
\hline Palpitation & & $2(12.5 \%)$ & 0.174 \\
\hline Gl reflux & & $2(12.5 \%)$ & 0.174 \\
\hline $\begin{array}{l}\text { Burning } \\
\text { micturition }\end{array}$ & $1(7.14 \%)$ & $3(18.755)$ & 0.613 \\
\hline Tinnitus & & $1(6.25 \%)$ & 1 \\
\hline $\begin{array}{l}\text { Blurring of } \\
\text { vision }\end{array}$ & & $1(6.25 \%)$ & 1 \\
\hline Constipation & & $2(12.5 \%)$ & 0.492 \\
\hline Diarrhoea & $1(7.14 \%)$ & & 0.133 \\
\hline $\begin{array}{l}\text { Blackening of } \\
\text { arm and } \\
\text { Forearm allergic } \\
\text { reactions }\end{array}$ & $4(28.57 \%)$ & $2(12.5 \%)$ & 0.354 \\
\hline Mouth sores & $1(7.14 \%)$ & & 0.133 \\
\hline
\end{tabular}

\begin{tabular}{|llll|}
\hline $\begin{array}{l}\text { Pustules around } \\
\text { mouth }\end{array}$ & $1(7.14 \%)$ & & 0.133 \\
\hline Fever & $2(14.28 \%)$ & & 0.174 \\
\hline Head ache & $1(7.14 \%)$ & & 0.133 \\
\hline Thrombophbelitis & $4(28.57 \%)$ & $1(6.25 \%)$ & 0.133089 \\
\hline Neutropaenia & $9(64.28 \%)$ & $7(43.75 \%)$ & 0.09821 \\
\hline Eosinophilia & $6(42.85 \%)$ & $6(37.5 \%)$ & 0.50832 \\
\hline Anaemia & $8(57.14 \%)$ & $5(31.25 \%)$ & 0.062942 \\
\hline $\begin{array}{l}\text { Thrombocytope- } \\
\text { nia }\end{array}$ & $3(21.42 \%)$ & $2(12.5 \%)$ & 0.623932 \\
\hline
\end{tabular}

\section{DISCUSSION}

In this study, adverse reactions- hematological and extra hematological were reported in both FAC and PAC regimens supported by previous studies. The commonly reported adverse reactions in patients undergoing PAC regimen were hematological. ${ }^{5}$ The incidence of neutropenia in these patients was $64.28 \%$ while that of anemia was $57 \%$. Eosinophilia had an incidence of $42 \%$ indicating allergic reactions despite corticosteroid administration in PAC regimen.

The prominent extra hematological adverse reactions were alopecia $(92.85 \%)$ and melanonychia (57\%) reported with PAC regimen which was not significant when compared with FAC regimen.

The common adverse reactions associated with FAC regimen were alopecia followed by nausea and vomiting. ${ }^{6}$ Infusion related adverse reactions like Thrombophlebitis was higher with PAC regimen (21.42\%).

The incidence of bone marrow depression reflected in the form of neutropaenia, anemia and thrombocytopenia was comparatively higher with PAC based treatment than FAC regimen, though there was no significant statistical data. $^{7}$ About three patients on PAC regimen $(21.4 \%$ ) required administration of filgastrim to increase their total count, whereas no such drugs were required for the patients on FAC therapy.

In patients on FAC regimen, about $75 \%$ of patients reported nausea and vomiting despite antiemetic use. Extra hematological reactions like Nausea and Vomiting was higher with FAC regimen which favours PAC therapy with a significant $\mathrm{p}$ value of 0.030287 .

Though adverse reactions were reported in both regimens, those associated with FAC were categorized as mild and those with PAC were designated as mild to moderate according to WHO scale of adverse reactions. No severe adverse reactions warranting discontinuation of treatment were reported.

The limitation of this study was the sample size is small and therefore we could not prove statistically significant 
difference between the adverse reaction profile of PAC and FAC regimens.

\section{CONCLUSION}

In conclusion, no severe adverse reactions were reported in either regimen. Though statistically not significant, FAC regimen has a favourable adverse reaction profile when compared with PAC regimen, independent of the potency and efficacy of these regimens in the treatment of patients with or without metastatic breast cancer.

\section{ACKNOWLEDGEMENTS}

Authors would like to thanks to Department of Oncology, Tirunelveli Medical College, Tamil Nadu, India.

\section{Funding: No funding sources}

Conflict of interest: None declared

Ethical approval: The study was approved by the Institutional Ethics Committee

\section{REFERENCES}

1. Breast cancer statistics. Available at www.wcrf. org/int/cancer-facts-figures.

2. National cancer registry program. Ten year consolidated report of the hospital based cancer registries, 1984-1993, an assessment of the burden and care of cancer patients. New Delhi: Indian Council of Medical Research; 2001.

3. Dear RF, McGeechan K, Jenkins MC, Barratt A, Tattersall MH, Wilcken N. Combination versus sequential single agent chemotherapy for metastatic breast cancer. Cochrane Database Syst Rev. 201318;12:CD008792.

4. Henderson IC, Berry DA, Demetri GD, Cirrincione $\mathrm{CT}$, Goldstein LJ, Martino $\mathrm{S}$, et al. Improved outcomes from adding sequential paclitaxel but not from escalating doxorubicin dose in an adjuvant chemotherapy regimen for patients with nodepositive primary breast cancer. Journal of Clinical Oncology. 2003;21(6):976-83.

5. Jassem J, Pieńkowski T, Płuzańska A, Jelic S, Gorbunova V, Mrsic-Krmpotic Z, et al. Doxorubicin and paclitaxel versus fluorouracil, doxorubicin, and cyclophosphamide as first-line therapy for women with metastatic breast cancer: final results of a randomized phase III multicenter trial. Central and Eastern Europe and Israel Pacitaxel Breast Cancer Study Group. J Clin Oncol. 2001;19(6):1707-15.

6. Martin M, Villar A, Sole-Calvo A, Gonzalez R, Massuti B, Lizon J, et al Doxorubicin in combination with fluorouracil and cyclophosphamide (i.v. FAC regimen, day 1,21$)$ versus methotrexate in combination with fluorouracil and cyclophosphamide (i.v. CMF regimen, day 1, 21) as adjuvant chemotherapy for operable breast cancer: a study by the GEICAM group. Ann Oncol. 2003;14(6):833-42.

7. Martín M, Lluch A, Seguí MA, Ruiz A, Ramos M, Adrover E, et al. Toxicity and health-related quality of life in breast cancer patients receiving adjuvant docetaxel, doxorubicin, cyclophosphamide (TAC) or 5-fluorouracil, doxorubicin and cyclophosphamide (FAC): impact of adding primary prophylactic granulocyte-colony stimulating factor to the TAC regimen. Ann Oncol. 2006;17(8):1205-12.

Cite this article as: Rani G, Celia D, Ramya E, Balasubramanium M. A comparative study of adverse reactions of taxol and non taxol based chemotherapy regimens in breast cancer. Int J Basic Clin Pharmacol 2016;5:1660-3. 